\title{
Ensaio sobre o negacionismo científico em tempos de pandemia
}

\author{
Essay on scientific denial in times of pandemic \\ Ensayo sobre la negación científica en tiempos de pandemia
}

Recebido: 17/08/2021 | Revisado: 21/08/2021 | Aceito: 22/08/2021 | Publicado: 23/08/2021

\author{
Francisco Caruso \\ ORCID: https://orcid.org/0000-0002-5481-9762 \\ Centro Brasileiro de Pesquisas Físicas, Brasil \\ E-mail: caruso@cbpf.br ou francisco.caruso@gmail.com \\ Adílio Jorge Marques \\ ORCID: https://orcid.org/0000-0002-9341-5357 \\ Universidade Federal dos Vales do Jequitinhonha e Mucuri, Brasil \\ E-mail: adiliojm@yahoo.com.br
}

\begin{abstract}
Resumo
A crítica de qualquer conceito passa necessariamente pela capacidade de se compreender suas origens e sua esfera de alcance. Talvez um dos legados mais tristes da pós-modernidade seja o negacionismo, quando se compreende que ele faz parte de uma estratégia de dominação a partir de uma guerra declarada à Ciência e à Razão. O escopo principal desse ensaio é, portanto, colocar algumas questões básicas sobre a origem do negacionismo científico na mesa, ainda que para elas não se tenham respostas definitivas. Por exemplo, em que medida ele se insere num processo de valorização do fanatismo e do individualismo? A falta de uma divulgação científica institucionalizada pode ser considerada uma causa do negacionismo vigente em nosso país? Está o negacionismo relacionado ao problema geral da educação? Há como identificar seus pilares na sociedade contemporânea? Essas são algumas perguntas que serão discutidas aqui, para as quais é urgente que se encontrem respostas, se desejamos evitar um enorme retrocesso sociocultural.
\end{abstract}

Palavras-chave: Negacionismo histórico; Educação; Divulgação científica.

\begin{abstract}
Criticism of any concept necessarily involves the ability to understand its origins and scope. Perhaps one of the saddest legacies of post-modernity is denial, when it is understood that it is part of a strategy of domination based on a declared war on Science and Reason. The main scope of this essay is, therefore, to put some basic questions about the origin of scientific denial on the table, even though for them there are no definitive answers. For example, to what extent is it part of a process of valuing fanaticism and individualism? Can the lack of institutionalized scientific dissemination be considered a cause of the current negationism in our country? Is negationism related to the general problem of education? Is there a way to identify its pillars in contemporary society? These are some questions that are discussed in this paper, to which it is urgent to find answers if we are to avoid a huge sociocultural setback.
\end{abstract}

Keywords: Historical negationism; Education; Scientific popularization.

\section{Resumen}

La crítica de cualquier concepto implica necesariamente la capacidad de comprender sus orígenes y alcance. Quizás uno de los legados más tristes de la posmodernidad sea la negación, cuando se entiende que forma parte de una estrategia de dominación basada en una guerra declarada a la Ciencia y la Razón. El objetivo principal de este ensayo es, por tanto, poner sobre la mesa algunas cuestiones básicas sobre el origen de la negación científica, aunque para ellas no existen respuestas definitivas. Por ejemplo, ¿en qué medida forma parte de un proceso de valoración del fanatismo y el individualismo? ¿La negación está relacionada con el problema general de la educación? ¿Existe alguna forma de identificar sus pilares en la sociedad contemporánea? Estas son algunas preguntas que si discutirá en este artículo, a las que es urgente encontrar respuestas si queremos evitar un gran revés sociocultural.

Palabras clave: Negacionismo histórico; Educación; Divulgación científica.

\section{Introdução}

O negacionismo - com toda sua carga de obscurantismo, arrogância e ignorância - é a tendência de negar aquilo que é real como estratégia de escapar de uma realidade incômoda ou inconveniente para um indivíduo, um grupo de pessoas ou um setor da sociedade, incluindo governos. Um recente exemplo emblemático foi quando, comentando a diferença entre a 
estimativa de presentes à posse de Donald Trump e a evidência mostrada em vídeos e fotografias, a Casa Branca, com base em uma declaração de Kellyanne Elizabeth Conway, em 2017, defendeu a existência de "fatos alternativos".

Em nossa opinião, essa tendência negacionista (sempre mentirosa) tem raízes múltiplas e profundas - nem sempre fáceis de serem identificadas - que, não obstante, devem ser reconhecidas e investigadas com cautela e urgência. Grosso modo, tal tendência nos parece relacionar-se ao crescente aumento do individualismo da sociedade contemporânea pós-industrial, assim como à tentativa de destruição da memória no sentido histórico, como teremos oportunidade de discutir ao longo desse ensaio.

O termo "negacionismo" aparece no cenário pós II Guerra Mundial referindo-se especificamente ao questionamento da existência do Holocausto (ver, por exemplo, filme Negação, 2016). A partir de então, ampliaram-se suas utilizações e surgiram outras vertentes para o emprego desse vocábulo. Podemos assim, por exemplo, falar de um negacionismo histórico e de um negacionismo científico. Contudo, destacamos que, no presente artigo, nosso foco principal é no segundo tipo, ou seja, o científico.

Inicialmente, cabe ressaltar que qualquer forma de negacionismo deve ser enfrentada de frente e colocada na pauta dos debates urgentes sobre que tipo de sociedade estamos a construir, pois aceitá-lo passivamente apresenta graves ameaças à liberdade e à civilidade, como será visto mais adiante, muitas das quais têm sido equivocadamente minimizadas pelas pessoas.

De fato, não há nada de ingênuo, nem de glamoroso, na defesa de qualquer tipo de negação. Ao contrário, é preciso explicitar que sua adoção é uma tática que faz parte de uma guerra aberta à razão, alcançando a ciência, a cultura e a própria sociedade. Essa grave tendência contemporânea deve, portanto, ser denunciada em toda sua amplitude e combatida, sob pena de caminharmos para tempos sombrios em que prevaleça um obscurantismo cultural, podendo, inclusive, assombrar a democracia. Compreender suas raízes faz-se, destarte, imperativo e o presente ensaio é dedicado a dar uma contribuição nesse sentido.

Em particular, o negacionismo científico procura defender o indefensável: a valorização cega da ignorância e do "achismo" em detrimento do conhecimento científico, com o objetivo de confundir e manipular a opinião pública, criando um terreno propício às fake news, como instrumento eficaz de manipulação.

Não se pode esquecer que a Ciência há muito se afastou de dogmas. Ela não se baseia em ideologias e sempre busca a Verdade, embora admitamos que esta é provisória, devendo ser constantemente testada com base na razão e na experimentação. No fundo, foi essa escolha que fez a episteme ser valorizada e se desenvolver alheia à opinião (doxa), o que, em última análise, resultou em um enorme impacto sobre o desenvolvimento da Humanidade, ainda que desigual. Logo, na Ciência não cabem "fatos alternativos". O reconhecimento de seu exitoso papel na criação da sociedade pós-moderna deveria bastar e servir para impedir que um conceito tão absurdo quanto o de "fato alternativo" fosse cogitado nessa sociedade: fatos são fatos.

Além disso, não é difícil perceber que o negacionismo científico contribui ainda para a manutenção do status quo de um país que aposta cada vez mais na comercialização de commodities, desistindo de ingressar de vez - e de lá se manter - no grupo dos países mais industrializados, que conquistaram seus altos níveis de desenvolvimento a partir de um apoio maciço e sistemático à Ciência e à Tecnologia (C\&T). Evidentemente, esses são também os países mais ricos e com maiores índices IDH. Negar o papel desenvolvimentista de C\&T é optar pelo subdesenvolvimento e pela estagnação social. Vamos explicitar melhor esse ponto a seguir a partir de exemplos históricos.

A Revolução Industrial teve início na segunda metade do século XVIII, na Inglaterra, com a mecanização dos sistemas de produção. Enquanto na Idade Média a manufatura era a forma de produzir mais utilizada, na Idade Moderna tudo mudou a partir de uma nova cosmovisão mecanicista, de origem técnico-científica. A burguesia industrial, ávida por maiores 
lucros e menores custos, e desejosa de acelerar sua produção, buscou alternativas para melhorar a produção de mercadorias e investiu no desenvolvimento e produção de máquinas industriais.

Em 1698, Thomas Newcomen (1663-1729) inventou uma máquina para drenar a água acumulada nas minas de carvão - a primeira máquina movida a vapor, patenteada em 1705. Essa foi uma típica invenção por tentativa e erro, desenvolvida para resolver um problema técnico específico, importante para o bom funcionamento das minas. No entanto, cinquenta anos depois, essa máquina veio a ser aperfeiçoada, a partir de estudos científicos e técnicos de James Watt (1736-1819). Os motores de Watt começam a ser construídos, em 1785, pelo industrial Matthew Boulton (1728-1809). Este invento impulsionou a Revolução Industrial e serviu de base para uma mudança espetacular que veio para ficar: a mecanização de toda a indústria, com enormes impactos na economia, nas relações de produção e na sociedade como um todo.

Ainda mais profunda foi a relação que vai se seguir entre o desenvolvimento das pesquisas científicas em torno do estudo do calor, da teoria cinética dos gases, da termodinâmica ${ }^{1}$ e da eletricidade e do magnetismo, por um lado, e suas aplicações práticas de significativo impacto transformador. ${ }^{2}$

Do ponto de vista técnico-científico, ressaltamos o aprimoramento da máquina a vapor, a invenção do dínamo e do motor à combustão como consequência direta dos frutos da pesquisa básica. Por outro, devemos considerar o impacto dessas descobertas sobre a Segunda Revolução Industrial na Inglaterra, no final do século XIX, que mudou de vez o panorama mundial. Mas o leitor pode se perguntar: relação mais "profunda" em que sentido? Embora se saiba que os frutos da Primeira Revolução Industrial dependeram do desenvolvimento técnico-científico, tal dependência é muito mais nítida e imbricada quando se trata da Segunda Revolução Industrial. Em nossa opinião, sua profundidade reside no fato de que é a partir desse momento que se pode afirmar não haver mais desenvolvimento tecnológico sem desenvolvimento científico (Caruso, 2013). A partir de então, diferencia-se a técnica da tecnologia, sendo essa última uma consequência direta dos avanços teóricos da Ciência, enquanto a técnica pode se desenvolver por um acúmulo de experiência baseada na tentativa e erro.

Tudo isso muda as formas de organização do trabalho, como percebeu Karl Marx (1818-1883), agora direcionado para alcançar maior produtividade e maiores lucros, empregando máquinas mecânicas e eletromagnéticas. Com base em análises da sociedade pós Segunda Revolução Industrial, a concepção marxista de homem fundamenta-se nas suas relações de produção tendo por base dois conceitos: o de alienação e o fetichismo de mercadoria decorrentes da mais valia ${ }^{3}$ (Marx, 2004).

Em meio a toda essa mudança de paradigma, o início do século XX presencia - com Taylor e Ford - uma transformação permanente do mercado, da produção, do consumo, das técnicas e, naturalmente, da própria vida das pessoas, como nos ensina o sociólogo italiano Domenico de Masi (2003).

Marx foi capaz de antever graves consequências nessas mudanças ao cunhar a conhecida expressão "tudo que é sólido desmancha ano ar", antecipando, de certa forma, o sujeito líquido (Bauman, 2000) do sociólogo e filósofo polonês Zygmunt Bauman (1925-2017). Além disso, Marx antevê com clareza o quanto a supervalorização dos bens materiais afetará o caráter humano. Mais tarde, o sociólogo norte-americano Richard Sennett (1943- ) verá a origem da corrupção do caráter ligada às novas relações de trabalho (Sennett, 2003). De qualquer forma, essa sociedade eminentemente industrial foi superada e

\footnotetext{
${ }^{1}$ Veja Caruso (2013).

${ }^{2} \mathrm{O}$ impacto da fabulosa síntese teórica de Maxwell propiciou a criação do dínamo e dos primeiros motores elétricos, essenciais para a Segunda Revolução Industrial na Inglaterra (Caruso, 2013). Dentre as várias consequências dessa Revolução, podemos citar uma que veio para ficar: a produção em série, na qual tudo passa a ser produzido de maneira uniforme e padronizada.

${ }^{3}$ Alienação aqui se refere à separação do indivíduo do produto de seu trabalho, ao qual ele, muitas vezes, não tem acesso e com o qual não se identifica, devido à sua contribuição diluída em uma linha de montagem, cujo ícone é a produção em massa apregoada posteriormente pelo fordismo. Com o conceito de fetichismo de mercadoria, Marx apontou que, no capitalismo, tudo tem preço: o trabalho do homem, o próprio homem e até valores superiores tais quais o amor e a honra, por exemplo (Caruso \& Moreira, 2020). O impacto social disso foi enorme e ainda pode ser percebido hoje em dia.
} 
vivemos hoje, segundo Domenico de Masi (1938- ), uma sociedade do conhecimento, na qual se destacam a Ciência e a criatividade (De Masi, 1999).

Assim, o século XX testemunhou a paulatina substituição do que se pode chamar de Sociedade Industrial, centrada na produção de bens materiais, por uma Sociedade pós-industrial, caracterizada pela produção de bens não materiais. As máquinas mecânicas e elétricas estão sendo substituídas por máquinas digitais, robôs e inteligência artificial. É o novo tempo propiciado pelo computador, fruto direto de um conhecimento científico de vanguarda. ${ }^{4}$

Desse modo, parece não haver dúvida de que, cada vez mais, é evidente que os avanços científicos e tecnológicos ditam o ritmo das transformações na sociedade atual, com grande impacto nas relações humanas e na forma como as pessoas se relacionam com o trabalho, com outras pessoas e com o próprio mundo.

Por mais paradoxal que seja, numa época na qual é cada vez mais fácil e rápido o acesso à comunicação, vemos uma exacerbação do individualismo, do egoísmo. Estamos de acordo com Domenico de Masi, quando ele afirma ser o egoísmo essencial ao projeto neo-liberal (De Masi, 2020). Em suas palavras, "Os economistas se enamoraram do liberalismo. Todo o mundo estava partindo da ideia de que o ser humano era egoísta, que o mercado era importante e que a economia tinha que sobressair sobre a política, e que o mercado financeiro tinha que prevalecer sobre a economia" (De Masi, 2020).

Por outro lado, há quem defenda que o não compartilhamento esperado das conquistas científicas seja um problema intrínseco à Ciência e que, assim sendo, ela deve ser criticada. Criticada sob o ângulo epistemológico, tendo como meta o progresso científico, sim, mas nunca desprezada. É verdade que enquanto a engenharia genética vem propiciando aumentos significativos nas safras de grãos e outros produtos, a fome não é erradicada no planeta e os avanços da medicina não chegam à enorme maioria da população (Caruso, 2013), só para citar dois exemplos. Há, efetivamente, sucessos científicos e tecnológicos que não necessariamente levaram a uma melhor qualidade de vida da maioria das pessoas, como muitos cientistas, filósofos e sociólogos apregoam ser um corolário inequívoco do desenvolvimento científico. Isso, no entanto, não é responsabilidade do cientista, tampouco pode ser entendido como um limite intrínseco à Ciência. Pois, de fato, qualquer impacto social das conquistas científicas depende, em última análise, de decisões políticas, econômicas e sociais, nem sempre triviais e nem sempre pautadas em critérios genuinamente objetivos voltados para o bem-estar coletivo. E exatamente nesse ponto o egoísmo e a correlata falta de empatia desempenham um triste papel determinante. Portanto, o utilitarismo não pode e não deve ser usado como argumento contrário ao papel positivo da Ciência no desenvolvimento da Humanidade.

Por fim, cabe notar que, da mesma forma que em outros momentos da História, a desinformação científica deliberada difunde uma sensação generalizada de falsas "certezas", minando a própria percepção da realidade e dando asas à "arrogância da ignorância". Essa tendência cria enorme confusão ao disseminar "verdades" pseudocientíficas e é extremamente nociva à sociedade como um todo. Esse fenômeno, a partir das redes sociais, pode facilmente se difundir em larga escala, uma vez que atinge pessoas de todas as classes sociais e formações acadêmicas. Cresce e se propaga, em última análise, no fértil solo da falta de espírito crítico aliado a ressentimentos, dogmas, e ao individualismo crescente, enraizados no neoliberalismo. É imperativo, portanto, que se faça um esforço coletivo para se entender o porquê enveredamos por esse caminho e para onde ele aponta.

Na Seção 2, apresenta-se uma descrição sucinta da metodologia empregada. Na Seção 3, discute-se o papel do fanatismo como uma possível raiz do negacionismo e de que forma grupos políticos dele podem se apropriar, transformando-o em um eficiente instrumento de manipulação de massas. Na Seção 4, aborda-se a influência de um processo revisionista da História na aceitação e propagação do negacionismo.

\footnotetext{
${ }^{4} \mathrm{O}$ impacto dos desenvolvimentos teóricos da Física Moderna sobre a construção de um novo mundo, de uma nova tecnologia, de uma nova ordem foi discutido em Caruso (2013).
} 
Uma terceira vertente que contribui para essa crescente onda, em escala global, relaciona-se com a excessiva individualidade resultante do capitalismo, com grave impacto sobre o caráter das pessoas, como nos ensina Sennett, e será tratada na Seção 5.

Enfim, questiona-se, na Seção 6, o que esperar da Educação formal no processo de enfrentamento do negacionismo e o papel (se é que há) da divulgação científica sobre a reversão dessa tendência quase universal. Alguns comentários finais são apresentados na Seção 7.

\section{Metodologia}

Trata-se de um ensaio, que, portanto, traz reflexões ligadas a uma vasta experiência didática dos autores e aos seus envolvimentos marcantes na área de divulgação científica durante décadas. Se, por um lado, o texto baseia-se em uma pesquisa documental, também é verdade que envolve uma pesquisa reflexiva, de caráter qualitativo (Estrela, 2018). O presente ensaio baseia-se, ainda, em pesquisa descritiva utilizando o método de revisão bibliográfica (Thomas, Nelson \& Silverman, 2007).

\section{Raízes no Fanatismo}

Uma possível causa geral do negacionismo pode ser o fanatismo. Amós Oz (1939-2018), escritor israelense crescido na Jerusalém dividida pela guerra, nos diz - em seu livro Como curar um fanático (2016) - que a mente do paranoico não tem senso de humor e não sabe rir de si mesma; no lugar disso, impera o ressentido, que faz com que os sentimentos predominem sobre a razão. Esse sujeito carrega um conceito exagerado de si mesmo, podendo ter ideias de perseguição e grandeza extremada. O paranoico agarra-se a um suposto "conhecimento", imaginando que este saber possa explicar aquilo que nada mais é do que senso comum, estabelecendo, a partir daí, relações espúrias de causa e efeito, em uma lógica deturpada muito pessoal. Eis o que o aproxima do fanático de toda espécie. Assim, o caminho do extremismo está traçado. Surgem os ressentidos. Esses, por sua vez, se caracterizam por afirmar que todo o mal advém da política. Entretanto, por mais paradoxal que pareça, os paranoicos creem que alguns políticos populistas são capazes de apontar soluções, desde que baseadas em sua visão estereotipada de mundo.

Embora a obra de $\mathrm{Oz}$ trate de casos extremos, como a guerra no Oriente Médio, não é difícil aceitar que os momentos de crise - como, por exemplo, a atual pandemia de Covid-19 - movem as pessoas em busca de explicações religiosas ou mesmo "mágicas" (e/ou esdrúxulas) para os males sociais ligados às condições de vida e de morte (Vasconcelos, 2010). Temos outros exemplos na História de momentos graves de crise sanitária nos quais as pessoas recorreram a algum tipo de fé, como na época da grande Peste Negra na Europa.

Talvez, de certa forma, tentar compreender os mistérios e as tragédias humanas, como a morte, tenha levado os primeiros homens a buscar explicações mais generalistas e mesmo fora do alcance dos mortais. Algo transcendental que, de certa maneira, talvez tenha sido necessário para a perpetuação da própria humanidade na formação civilizacional (Peterson, 1999). Assim, grandes eventos catastróficos, como a já citada Peste Negra na Idade Média, a Gripe Espanhola e a atual pandemia e outras tragédias, poderiam levar parte da sociedade novamente a esse pensamento ancestral, mítico, atávico, que via na natureza ou no fatalismo (destino) explicação para tudo, mesmo para o que não podia ser mensurado ou explicado, aquilo regido pelos deuses.

Alternativamente, sabemos que o pensamento científico carrega limitações intrínsecas ao seu método essencialmente racional - sem recorrer a explicações mítico-poéticas do que quer que seja. Além disso, não desperta sensações e emoções, como, por exemplo, as envolvidas em um drama. A Ciência, tal qual a conhecemos hoje, depende da permanente aceitação de "saber que nada sabe", sem qualquer dogmatismo a priori. Note bem que a busca da Verdade não é incompatível com qualquer tipo de incompletude ou com a aceitação de que toda verdade científica possa ser provisória. Essa característica 
marcante, reconhecemos, é de difícil aceitação pelo senso comum. Contudo, pessoas que valorizam o pensamento míticoreligioso acima de tudo veem os fatos históricos como parte de uma espécie de "roteiro universal" dos eventos, em especial nos trágicos, sendo que todos aqueles que não codividem essa cosmovisão seriam incapazes de compreendê-los. Essa seria uma possível explicação para a ignorância, ou seja, para a falta de escolaridade e de discernimento que não leva os indivíduos a duvidar das fake news.

Nas teorias negacionistas, assim como no pensamento mítico-religioso, há sempre certa relação com o desconhecido, o metafísico; relação essa que alude a um pretenso conhecimento divino, inalcançável pela Ciência. Logo, há um esforço, por parte de ideólogos dessa crença, no sentido de difundir esse tipo de pensamento de cunho pretensamente religioso, como parte de uma estratégia para que tenham maior influência e controle sobre as pessoas e poder político. Em termos gerais, essa estrutura de pensamento mítico, tem raízes no pensamento religioso judaico-cristão.

Em contrapartida, o pensamento científico, tal como se desenvolveu na era moderna a partir da seminal contribuição de Galileu Galilei (1564-1642) (Geymonat, 1997), baseia-se em fatos e comprovações - e não na opinião - adotando a Matemática como linguagem. Galileu fez, na verdade, um grande esforço para manter as questões científicas fora das disputas religiosas e mais afastadas possível da doxa.

De outro ponto de vista, em linhas gerais, o psicólogo canadense Jordan Bernt Peterson (1962- ) enfatiza que o surgimento de uma cosmovisão científica na História da Humanidade deu-se há relativamente pouco tempo, comparado com o tempo do pensamento mítico e dramático, o que pode delongar o processo de assimilação desse tipo de pensamento pelo senso comum. Na civilização ocidental, foi apenas a partir da filosofia grega que passamos a tentar separar o pensamento racional do mitológico. Sob o aspecto intelectual, esse é um dos maiores legados da História, que moldou o pensamento Europeu e o de todo Ocidente.

No Medievo encontra-se talvez o melhor exemplo do tipo de controle social e cultural, uma vez que a sociedade medieval, essencialmente teocêntrica, abraçava uma concepção para a Criação dominada pela figura de Deus como o centro do universo e como medida de todas as coisas. Esse era, do ponto de vista filosófico, o Cosmos de Aristóteles (384 a.C.-322 a.C.), finito e hierarquizado. Tal ideia é muito importante para a doutrina cristã baseada no pressuposto da existência de uma providência geral perante o universo e o destino do homem (Caruso \& Moreira, 2020). Para ficar clara a motivação da Igreja Católica ao adotar o Cosmos aristotélico, podemos recorrer à justificativa sucinta oferecida por Mircea Eliade (1907-1986), estudioso romeno das Religiões. Segundo ele, o espaço não é homogêneo para o homem religioso e isso, sustenta, constitui uma experiência primordial que corresponde, em certo sentido, a uma "fundação do Mundo". Em suas palavras (Eliade, 2013, p. 25): "Para o homem religioso essa não-homogeneidade espacial traduz-se pela experiência de uma oposição entre o espaço sagrado - o único que é real, que existe realmente - e o resto, a extensão informe, que o cerca". Ainda, como bem resumem Caruso E Moreira (2020, p. 36), entendemos que "A revelação desse espaço sagrado hierarquizado tem um valor existencial para o homem religioso à medida que essa hierarquia, em última análise, permite, simultaneamente, a criação do Mundo e a definição de um "ponto fixo", a partir do qual se constrói um sentido de orientação necessária para a sua compreensão desse Mundo". É por essa razão, conclui Eliade, "que o homem religioso sempre se esforçou por estabelecer-se no "Centro do Mundo"'” (Eliade, 2013, p. 26).

Hoje em dia, em especial no Brasil, assim como nos EUA, essa tendência negacionista é ligada a algumas vertentes religiosas de matriz protestante, visando legitimar um suposto acesso à fonte ilimitada de conhecimento - o próprio Deus excluindo, no entanto, o conhecimento científico, responsável pela Dissolução do Cosmos aristotélico a partir da publicação do 
De Revolutionibus Orbium Coelestium de Copérnico, proibido pela Igreja em 1616. Obviamente, essa escolha não é nem única nem obrigatória e discuti-la aqui estaria fora do escopo do ensaio. ${ }^{5}$

Aqui, é preciso que fique claro que a defesa do negacionismo, como já mencionado, é sempre um ato de guerra à razão, declarado aberta e conscientemente ou não: uma guerra à razão que se amplia como morte à razão, na perspectiva de uma necropolítica sustentadora do modo de produção capitalista, no Brasil de hoje.

Um exemplo histórico clássico de fundamentação mítica do negacionismo é o que foi perpetrado contra a cultura pelo nazismo na Alemanha. Naquela época (1933), milhares de livros foram queimados em lugares públicos (Bücherverbrennung), como parte de um projeto de ataque ao saber científico e à cultura, que nos remete ao futuro distópico de Fahrenheit 451 (Bradbury, 2020), originalmente publicado em 1953. Nele, o autor nos faz refletir sobre o ódio e o temor ao livro - as ideias escritas - sem o qual não somos capazes de transmitir nossas recordações e histórias a outras gerações. Queimar livros é uma tentativa deliberada de pôr fim à História, principal instrumento de construção de uma sociedade aberta, deixando o homem egoisticamente solitário. E lembre-se, como disse o poeta Heinrich Heine: - "Onde se queimam livros, acaba-se queimando pessoas".

Paralelamente, houve, nesse período, por parte do nazismo, uma tentativa de resgate de tradições e cultos de um passado remoto idealizado e de reviver o misticismo germânico medieval. O instrumento disso foi uma enorme máquina de propaganda concebida por Joseph Goebbels (1897-1945), baseada na ideia de que uma mentira repetida inúmeras vezes tornase verdade, sobre a qual, infelizmente, a propaganda moderna ainda se alicerça. Mentir para convencer. Racismo, misticismo, ocultismo e obscurantismo passam a integrar uma das mais infames e nefastas ideologias da História da Humanidade.

Com relação a essas novas técnicas de comunicação, lembremos o que descreve o eminente filólogo Victor Klemperer (1881-1960) em seu importante livro LTI, a linguagem do Terceiro Reich (2009). A sua tese é a de que o nazismo se consolidou quando dominou a linguagem, quando novos termos, palavras adaptadas, mudaram de sentido e ênfase e passaram a emitir mensagens de interesse político do partido. Para, quem controla as formas como o povo se expressa, também controla o seu pensamento. Como destaca Miriam Bettina Paulina Oelsner, responsável pela tradução brasileira, apresentação e notas de LTI (Klemperer, 2009, p. 17):

Por meio de um estudo minucioso e metódico, Klemperer demonstra como o sentido dos conceitos foi sendo abandonado, de modo a empobrecê-los de propósito: o significado das palavras foi desvirtuado; o preparo físico foi valorizado em detrimento da capacidade intelectual; a camada social culta e instruída foi desvalorizada, estimulando o desinteresse cultural; o significado da palavra filosofia foi esvaziado por causa do perigo que o exercício do livrepensar poderia suscitar.

Ele estuda também a repetição sistemática de mentiras condicionadas aos interesses do regime. Explica como, a partir de um processo duplo de sedução e terror, os nazistas transformaram graves anomalias em normalidade, induzindo a sociedade a aceitar tudo como "natural".

Como também podemos perceber a partir da leitura do livro LTI (2009), parece existir, hoje em dia, certa dose de repetição em muitos dos ataques ao bom senso e à racionalidade. Assim como hodiernamente, no infame período do nazismo,

\footnotetext{
${ }^{5}$ De fato, nesse sentido, podemos citar René Descartes (1596-1650). Ele admite a existência de Deus e que Ele é único, onisciente, capaz de tudo perceber, pois é o próprio saber. Mas isso não o impede de valorizar a Ciência, imaginando Deus como causa final dos eventos físicos. Assim, segundo o filósofo francês, o homem só poderia compreender a Criação a partir do método analítico (Descartes, 2006). Ou seja, devemos saber com profundidade o pouco que a ciência consegue pesquisar, e ainda devemos buscar sempre a relação de causa entre as partes estudadas. Isto mostra que não se pode conhecer a universalidade dos saberes, algo sempre buscado pelo cientista, mas que se contrapõe ao pseudo-saber dos elementos mítico-paranoicos expostos neste texto, termo este por nós aqui cunhado para exemplificar como esse tipo de atitude não científica ganha "roupagem" de sabedoria dos antigos, como expressava Francis Bacon (1561-1626) em obra homônima (2002).
} 
até mesmo as suas vítimas acabaram por adotar expressões criadas pelo sistema, além de normalizar procedimentos muitas vezes violentos e visando abertamente atacar as condições democráticas de um Estado de direitos.

Estudos históricos detalhados, como os que desconstroem a noção de hegemonia racial conforme estudada por Victor Klemperer, nos mostram como a valorização utilitarista substituiu o valor da ciência, e como dominar o corpo passou a ser mais importante do que a educação na Alemanha dos anos 1930, alimentando uma eugenia da "aparência nórdica" - o mito da raça superior - e levando o serviço militar a ser revalorizado em um país ao qual a desmilitarização havia sido imposta com a perda da I Guerra Mundial. Eventos que levaram ao disfarce de uma pseudo-superioridade ariana que se esconderia por detrás de um uniforme - fosse militar ou esportivo - eram frutos desse culto ao corpo em detrimento do intelecto. Falsos heróis foram sendo construídos e corroendo a sociedade alemã de dentro para fora. Esse risco pode ser revivido ao se negar a Ciência e seus valores.

Atualmente, ainda vivemos em uma sociedade impregnada de propaganda, com toda a sua carga negativa já mencionada associada à mentira. ${ }^{6}$ Com o agravante de que a velocidade da circulação de informação, com o advento da internet, vem aumentando enormemente. Soma-se a isso a observação do escritor e filólogo italiano Umberto Eco (1932-2016) de que "as redes sociais deram voz a uma legião de imbecis". E nas redes é muito fácil propagar desinformação.

Concluindo essa Seção, pode-se afirmar que estamos vivenciando, no Brasil, um negacionismo científico imiscuído em um negacionismo de Estado. De fato, parte do governo brasileiro, escondendo-se atrás de um pensamento míticoparanoico, coloca-se em uma condição pretensamente "superior" em relação ao pensamento científico, contribuindo, desde o início, para o agravamento de nossa mais recente tragédia - a pandemia - defendendo tratamentos comprovadamente ineficazes e incentivando a não utilização de máscaras e demais cuidados básicos, insistindo que o distanciamento ou isolamento social não são necessários, chegando a afirmar que isso afetaria o direito de ir e vir.

Em nossa opinião, o contexto da atual crise sanitária indica certa apropriação da ignorância (no sentido do desconhecimento do método científico) por um grupo responsável por repassar ao público em geral, do alto de seu ressentimento pela vida e pela ciência, informações no mínimo equivocadas e contraditórias.

Não é difícil perceber claramente o quanto o cenário resultante desmotiva o jovem a se interessar pela Ciência, sem falar na crônica falta de apoio institucional às atividades científicas no Brasil (Ferreira \& Marques, 2019). Além disso, verificase o fenômeno de fuga de intelectuais e mão de obra qualificada de nosso país, em várias áreas de C\&T, como se percebe em muitas reportagens recentes, dentre as quais podemos mencionar a da BBC News Brasil (2020), "Fuga de cérebros: os doutores que preferiram deixar o Brasil para continuar pesquisas em outro país".

\section{Sentido e Flexibilização da História}

Nessa Seção, vamos lançar mão do conceito de disjunção para tentar entender como as ditas fake news (ou mesmo o negacionismo da ciência) podem penetrar nas várias camadas sociais de maneira indistinta.

Esse conceito é discutido pelo intelectual estadunidense Daniel Bell (1919-2011) em seu livro As Contradições Culturais do Capitalismo (1976). Bell explica que não parece existir um sentido teleológico para a História, e talvez não exista nem para os grupamentos humanos, as redes sociais, e a tecnologia. Ou seja, não há necessariamente uma organicidade real que nos conduza para um mundo melhor. Cada sociedade se orientaria na História por meio de suas escolhas, prescindindo da

\footnotetext{
${ }^{6}$ De certa forma, é curioso a continuada complacência da sociedade contemporânea para com a mentira sempre embutida na enorme maioria das propagandas, em contraposição a certo (embora ainda incipiente) criticismo com relação às fake news. Esse fato nos faz lembrar o clássico filme Blade Runner, passado num futuro distópico onde tudo é replicado geneticamente, inclusive os humanos. Aqueles banidos, enviados para colonizar outros planetas, que retornam à Terra precisam ser caçados e exterminados. Ainda não chegamos a esse ponto, mas nossa sociedade globalizada já se deu conta de que num mundo de réplicas fáceis é importante a criação de forças (talvez policiais análogas àquela do filme) voltadas para identificar essas fake news e "exterminá-las", denunciando-as (Nemer, 2021).
} 
crença de que tudo faz parte de um sentido maior e de um determinismo, de um telos ou finalidade. Não haveria um "espírito hegeliano" para a nossa História, ou seja, a ideia de um desenvolvimento teleológico da historicidade humana, levando à obrigatoriedade de se compreender isso pela própria História e pela Filosofia.

Dentro dessa perspectiva, lembremos que a Avaaz ${ }^{7}$ recentemente identificou algo importante em termos de Brasil. Esta organização realizou uma pesquisa em 2020 que ficou muito conhecida com o título "Brasil está sofrendo uma infodemia de Covid-19". Verificou-se que 73\% dos brasileiros acreditam em falsas notícias sobre a pandemia, o que corresponde a uma projeção de pouco mais de 150 milhões de pessoas. Essa é uma triste amostra não apenas do poder de penetração das redes sociais, mas também do pernicioso poder da desinformação científica veiculada em larga escala para a população. Essa mesma pesquisa (p. 2) ainda nos alerta para o seguinte:

De acordo com um estudo da Avaaz, 9 em cada 10 brasileiros entrevistados no país viram pelo menos uma informação falsa sobre a doença, e 7 em cada 10 brasileiros entrevistados acreditaram em, ao menos, um conteúdo desinformativo sobre a pandemia. Esses dados são ainda mais preocupantes quando comparados aos dos EUA e da Itália $(65 \%$ e $59 \%$, respectivamente).

O evento das "milícias digitais", muito atuantes nos últimos anos em vários países, é outro exemplo, como podemos ver nos trabalhos do brasileiro David Nemer, professor da Universidade da Virgínia, especialista em antropologia da Informática. Seu vasto trabalho evidencia o quanto as mídias extremistas podem radicalizar sua atuação quando descobertas e acuadas por qualquer fiscalização (Nemer, 2021).

Assim, as contradições impostas pelo capitalismo, hoje ainda mais fortes do que nunca em face à globalização, favoreceriam essas contradições gerais da vida, de maneira aleatória. E elas criariam espaços - "rachaduras" - na tessitura social e cultural das sociedades, algo que permitiria o surgimento de temas contraditórios e desintegradores como a "Terra plana", o criacionismo como negação do darwinismo, interferindo no ensino de Ciências, o movimento antivacina, entre outros, em confronto direto com as ciências, num processo que aproxima as religiões das explicações buscadas. Acreditamos, então, que há uma origem política do negacionismo brasileiro a partir da apropriação da ignorância por uma elite governamental, que, embora devesse ser laica, infelizmente se apropria de dogmas religiosos visando o controle da opinião pública. Parece haver uma relação intencional: se o povo acreditar nas fake news não questionará sua submissão ao poder que sustenta desigualdades sociais que o leva à perda de direitos e à miséria.

De certa forma, isso corrobora as ideias sobre como as novas relações de trabalho da sociedade pós-industrial afetam o caráter das pessoas, como nos ensina Richard Sennett, em sua obra A corrosão do caráter (2003), na qual ele descreve a suposta "flexibilização" que o capital provocou nas relações trabalhistas e sociais, inclusive nas relações entre o mercado e a cultura.

Sua premissa inicial é que o modo de produção atual pode colocar a vida emocional das pessoas à deriva. Estamos todos expostos a uma forte tendência de se "reinventar decisiva e irrevogavelmente às instituições, para que o presente se torne descontínuo com o passado". Justifica-se, assim, a dificuldade de os indivíduos construírem suas próprias histórias, a partir de suas experiências profissionais e de seus laços de dependência com outros indivíduos. Uma consequência direta desse fato é que as pessoas tendem a viver apenas o presente. Sonhar passa a ser mais difícil, quando as incertezas de se manter o que se conquistou profissionalmente se tornam significativas.

Sennett busca relatar em detalhes a passagem de um capitalismo de classe para um capitalismo flexível, fazendo com que valores como integridade e compromisso sejam substituídos por outros. Desse modo, para o autor, isso levaria a laços superficiais entre as pessoas no mundo do trabalho, em um primeiro momento, permeando em seguida, aos poucos, o restante

\footnotetext{
${ }^{7}$ A organização Avaaz.org é uma famosa rede para mobilização social global por meio da internet, fundada em 2007.
} 
do tecido social. Evidentemente, essa característica será espelhada pelos usuários das redes sociais. Algo que de certa forma mascara a atuação em grupo, mesmo em uma época de interesses individualistas:

As formas modernas de trabalho em equipe são em muitos aspectos o oposto da ética do trabalho como concebia Max Weber. Ética de grupo em oposição à ética do indivíduo, o trabalho em equipe enfatiza mais a responsabilidade mútua que a confirmação pessoal. O tempo das equipes é mais flexível e voltado para tarefas específicas de curto prazo do que para a soma das décadas caracterizadas pela contenção e a espera. O trabalho em equipe, porém, nos leva ao domínio da superficialidade degradante que assedia o moderno local de trabalho. Na verdade, o trabalho em equipe deixa o reino da tragédia para encenar as relações humanas como uma farsa. (Sennett, 2003, pp. 126-127).

A enorme flexibilização do trabalho, por um lado, busca uma adaptação rápida à sempre crescente volatilidade da demanda do consumidor e, por outro, implica a aceitação de que "não há longo prazo". ${ }^{8}$ Acreditamos, assim como o autor, que tal expressão contém o princípio da corrosão de valores como a confiança, a lealdade e o compromisso mútuo. Desse modo, o espectro da volatilidade se alarga, extrapola as fronteiras da Economia, e se infiltra nas relações sociais. Além disso, Sennett observa muito bem que, na área familiar, esta expressão significa "mudar, não se comprometer e não se sacrificar".

Essa flexibilização, como expressa pelo sociólogo e historiador estadunidense, pode ainda levar, em nosso entendimento, a destituir de veracidade a Ciência, dado que a reinvenção pelo capital às organizações do trabalho passaria também para as relações entre as pessoas, e destas para as demais áreas humanas e sociais. Se, em nome da modernização e avanço do capital, pudermos recriar as instituições, poderemos entender o cada vez mais explícito ataque à escola e às universidades, assim como a relativização de seu maior produto: a produção científica e intelectual, sem contar os resultados deletérios da crescente privatização do ensino, como se vê aqui no Brasil, minimizando o valor da pesquisa nas instituições privadas.

Esses princípios reguladores históricos estariam atuando sobre a corrosão do caráter desde o início do pensamento da sociedade capitalista, ou seja, ao menos desde o século XVIII, como Sennett (2003) nos diz:

... o pensamento filosófico sobre o caráter tem-se esforçado para encontrar princípios de regulação e recuperação interiores que resgatem o senso de individualidade do fluxo sensório. Nos textos após Adam Smith dedicados à economia política, porém, enfatizou-se a simples mudança. Esse tipo de flexibilidade foi associado a virtudes empresariais; após Smith, economistas políticos do século dezenove opuseram a agilidade do empresário à lerda morosidade do trabalhador industrial; John Stuart Mill, em seu 'Princípios de economia política', encarava os mercados como um teatro da vida ao mesmo tempo perigoso e desafiador, e seus comerciantes como artistas da improvisação. (Sennett, 2003, p. 54).

Se nas relações pessoais e trabalhistas ocorre uma "corrosão do caráter", é quase certo que todas essas questões acabam por se refletir, em alguma medida, na família e na escola. Uma das primeiras consequências dessa tendência é o predomínio do senso comum no ensino, que cresce a olhos vistos quando se trata, mesmo entre discentes, de uma análise geral do que nos cerca pelo prisma científico. Sabemos, por exemplo, que apesar de Aristóteles ter proposto sua Física enquanto discussão filosófica, muitas de suas explicações para vários conceitos deste saber, calcadas no senso comum, estavam equivocadas, porque se relacionavam aos limites dos parâmetros teóricos intrínsecos à época e que mais tarde foram revistos por Copérnico (1473-1543), Galileu Galilei e Isaac Newton (1643-1727) que estabeleceram as bases do pensamento físico sobe

\footnotetext{
${ }^{8}$ Aliás, "superficial" é uma palavra que designa bem os dias de hoje, quando se vê que os jovens não namoram mais, apenas "ficam". Essa expressão denota que, mesmo no campo afetivo ou do amor, se aceita como premissa que "não há longo prazo". Superficial é ainda o mundo do videoclip, o mundo globalizado onde alguns propalam vantagens globalizantes da Internet. Entretanto, não podemos esquecer que esta poderosa ferramenta é em si mesma também um convite à superficialidade. De fato, Tony Rothman, por exemplo, afirma, no livro Tudo é Relativo (2005), que "a Internet tem a largura de uma galáxia e a profundidade de um dedo".
} 
os movimentos, força, sistema solar etc. Contudo, alunos do Ensino Médio, ou seja, já em fase final da formação básica em nosso país, não sabem quem foi Galileu. E quase sempre não conseguem responder corretamente a questões de Física que distinguem o entendimento aristotélico dos movimentos (com muitas explicações dadas pelo mesmo senso comum) das interpretações galileanas da Física (Caruso, Marques \& Oguri, 2013). Esse fato deveria ser compreendido como um alerta para aqueles que defendem o ensino de Física Moderna nessa faixa de escolaridade. Como compreendê-la se o aluno não se desvencilhou do senso comum? Voltaremos a discutir sobre a escola na Seção 5.

\section{O eu e as Crenças}

Uma espécie de "recentramento" do eu, ou esse reforço da individualidade que o mercado imprime aos indivíduos, já era previsto desde John Locke (1632-1704), David Hume (1711-1776) e Adam Smith (1723-1790). Ou seja, tentamos sempre entender o papel do nosso eu - se ele existe mesmo - enquanto sujeitos ontológicos que somos. A eterna busca de compreender o que somos, enquanto bombardeados a cada momento por um número crescente de informações, poderá ter contribuído para os seres humanos se tornarem cada vez mais individualistas. Um paradoxo pós-moderno - termo cunhado nos anos 1980 pelo filósofo Jean-François Lyotard (1924-1998) - quando comparamos com a busca das explicações no universal.

Lyotard defende a tese de que o pós-moderno se baseia na recusa de narrativas longas sobre as coisas. E aqui não podemos deixar de trazer à memória Zygmunt Bauman, que desenvolveu a ideia de "consciência pós-moderna", ou seja, a consciência do fracasso da modernidade e das utopias que ela prometeu para a humanidade. Um fracasso por ele evidenciado também em sua obra Modernidade e holocausto (1989).

O homem pós-moderno do final do século XX e início do século XXI é, ao mesmo tempo, “vítima” e caracterizado pela fragmentação exagerada de tudo, que leva ao fenômeno que se pode chamar de descentramento do sujeito. Como apontado por Caruso \& Moreira (2020), a percepção que esse sujeito tem de si próprio e do Mundo se edifica em um espaço imaginário de dimensionalidade praticamente infinita, criado pela internet e pelas redes sociais. A implicada fragmentação do texto, da leitura, do espaço e do tempo cobra seu alto preço. Não é difícil imaginar que ela possa, em última análise, contribuir para a dissolução da identidade. De fato, há quem sustente que a percepção do cyberspace não desenvolve apenas uma multiplicidade de pontos de vista, mas também de um conjunto de "eus" (Santaella, 2016).

Segundo o artista britânico Roy Ascott (1934- ), vislumbra-se, a partir dessa tendência, uma recorrente redefinição do sujeito, capaz de criar múltiplas identidades que operam em diferentes sítios do ciberespaço. Esse "novo eu”, simultaneamente multiplicado, fracionado e disperso, aparenta ser fundamental à vida na net (Ascott, 1995). Além disso, parece-nos bastante evidente que esse novo sujeito busque pulverizar sua própria história. A negação permanente de seu passado e de suas raízes, de sua história, enfim, relacionam-se à corrosão de seu próprio caráter como aponta Richard Sennett, conforme já mencionado aqui.

Além disso, a preocupação com a administração cotidiana e o gerenciamento dessas múltiplas identidades parece distanciar o ser humano da reflexão moral bem como da dimensão ética. Esse fracasso trouxe os questionamentos da ciência que os negacionistas tanto propagam atualmente, e o exemplo da negação do holocausto evidencia o ápice da dinâmica e da violência contra a racionalidade na modernidade.

Para o filósofo polonês, a sociedade de consumo é imediatista, cria pessoas dependentes da felicidade gerada pelo consumo, produzindo relações fluidas, líquidas (termo cunhado por Bauman (2000) em oposição para com a "solidez" das certezas da modernidade), a flexibilização das ideias levada aos muitos setores da sociedade. É necessário compreender o tempo presente, bem como desenvolver outra ética para a nossa época: o que o filósofo chama de "ética do inverno". Ou seja, princípios éticos que nos façam compreender e agir, perante nós mesmos e os outros, em momentos de crise social e existencial (um tempo de intempéries), tal qual a pós-modernidade nos apresenta. Uma espécie de reconstituição do ser. O 
momento é crítico e faz com que entendamos a necessidade de uma nova perspectiva consciente diante da vida, e outra forma de relação com as condições habituais. E dentre as novas propostas que devem nos orientar, surge a da relação escolar e o despertar do interesse científico dos jovens, talvez as primeiras "vítimas" da liquidez das relações e das informações do mundo contemporâneo.

Ao que parece, a pós-modernidade evidencia que as crenças são difíceis de refutar, levando a teorias conspiratórias, pois fornecem ao autor a convicção de que alguma coisa é verdadeira, irrefutável, mesmo que baseada em raciocínios pessoais e quase sempre no senso comum. As redes sociais favoreceram muito a disseminação de negacionismos e ataques à ciência, assim como a formação de grupos como o movimento QAnon nascido nos EUA. O sentido de pertencimento é uma característica dessas pessoas que negam a realidade da ciência, e as redes sociais se mostram como vetor propício para tal manifestação. O paranoico acredita, por exemplo, que sabe algo muito importante que mais ninguém teria acesso, comportamento que, aliado aos acessos facilitados dos meios de comunicação, trouxe outra forma de se ver o mundo. Talvez por isso Umberto Eco tenha dito, em 2015, quando ganhou o título de Doutor Honoris Causa na Universidade de Turim (Itália), que as redes sociais estariam dando voz a uma "legião de imbecis", e que esses mesmos personagens antes não poderiam prejudicar a coletividade. Essa famosa declaração de Eco, embora possa parecer muito forte, vem se mostrando assertiva. No Brasil, no grave momento da pandemia de Covid-19, testemunhamos muitas pessoas alheias ao campo da Medicina tentarem vender a ideia de um tratamento precoce sem qualquer comprovação científica. A ignorância se manifesta no falso conhecimento científico (Marques, 2017).

A luz no fim do túnel poderá vir da aceitação do ceticismo filosófico como forma de análise da atual conjuntura negacionista em relação às ciências. Ou seja, um constante questionamento em relação aos fatos, independentemente dos meios pelos quais eles são veiculados para o público em geral, acompanhado do repúdio ao conceito de "fatos alternativos". Emil Cioran (1911-1995), filósofo romeno, nos mostra, em suas obras, o quanto a alienação e a angústia dos homens poderiam leválos, inclusive, a um forte pessimismo intrínseco nas atitudes em sociedade. O que poderia gerar certo desespero, podendo explicar a necessidade de se socorrer de visões generalistas daqueles que não possuem aprofundamento em determinados temas (Cioran, 2012).

\section{A Escola e a Divulgação Científica}

Nunca pensamos que, em pleno século XXI, assistiríamos um número expressivo de pessoas defendendo que a Terra é plana, Eratóstenes (276-195 a.C.) já havia mostrado que a Terra tem forma esférica.

Por mais absurda que essa situação possa parecer, devemos nos esforçar para tentar compreender o porquê da disseminação dessa atitude. É ela fruto de simples ignorância? É consequência da falta de educação científica ou de não ter tido contato com a divulgação da Ciência? Ou é decorrente de um problema geral da formação educacional das pessoas, ou ainda tem a ver com questões religiosas? Tais questões nos remetem ao problema da escola. Mas há ainda outras possibilidades externas a ela. Ou a tendência negacionista é fruto de outras posturas dogmáticas das pessoas ou de transformações pelas quais vem passando o sujeito (como abordado nas Seções anteriores)? Enfim, qual a origem do negacionismo crescente que estamos presenciando?

Todas essas questões merecem muita atenção por parte daqueles interessados em contribuir para uma divulgação científica efetiva em nosso país (Caruso, 2020). Não lhes dar a devida importância é tentar tapar o sol com a peneira.

É importante que se diga que a busca de compreender esse quadro complexo tangencia outra questão mais ampla e não menos importante, qual seja, a relação entre educação, cultura e vida civil. Referimo-nos aqui, por exemplo, ao assombro da humanidade ao constatar que pessoas com escolaridade elevada, cultas, que valorizam, especialmente, a cultura clássica, foram capazes de cometer as maiores atrocidades contra seus semelhantes, como foi o caso de muitos nazistas (Seção 2). 
Estaria o negacionismo diretamente relacionado ao problema geral da educação? Até onde sabemos, não há estudos nesse sentido. Em princípio, podemos imaginar que a resposta seria afirmativa. Entretanto, é preciso lembrar que a Regional Rio da SBPF, durante mais de uma década, levou adiante o Projeto SBPC vai à Escola, que levava pesquisadores das mais diversas áreas para darem palestras de divulgação científica em escolas das redes pública e privada. Entretanto, não parece haver um comportamento diferente da população do Rio de Janeiro em relação aos demais Estados que não vivenciaram experiência semelhante no que tange à divulgação científica. Claro está que na ausência de indicadores e de estudos formais, o real impacto desse Projeto é inconclusivo.

Essa questão, em toda sua complexidade, deve, na verdade. ser examinada dentro do contexto histórico da Educação no país que, ao que parece à primeira vista, sempre esteve em crise. Na realidade, concordamos com o antropólogo e escritor brasileiro Darcy Ribeiro (1922-1997) quando ele, com toda sua lucidez, afirmou: “A crise da Educação no Brasil não é uma Crise, é um projeto". ${ }^{9}$ Não há forma mais vil e eficiente de fomentar a servidão de um povo que através do analfabetismo e negando-lhe acesso a todos os níveis de escolaridade e à cultura, implícitos nesse indecoroso projeto. Além disso, como bem notou o filósofo Demócrito de Abdera (c. 460 a.C.), "O pior de todos os males é a leviandade no educar a juventude, pois é ela que gera aqueles prazeres de que nasce a maldade" (Santoro, 2007, p. 52).

De qualquer maneira, o apoio institucional, seja à área de Educação, seja à de Ciências, deve ser planejado e executado com políticas de longo prazo, da forma mais integrada possível, vendo ambas como atividades complexas e essenciais ao desenvolvimento de qualquer país hoje em dia. E não faltam exemplos históricos neste sentido.

Em relação à escola, independentemente do nível de escolaridade, há que se admitir que os padrões de qualidade têm diminuído significativamente no último século. Sennett, analisando a flexibilização do trabalho, vê um terrível paradoxo, no fato de que quando diminuímos a dificuldade e a resistência, criamos as condições mesmas para a atividade acrítica e indiferente por parte dos usuários (Sennett, 2013). Acreditamos que o mesmo tipo de paradoxo se aplique à escola. Alunos acríticos serão consumidores ideais. Outra característica do mercado que o autor destaca é que cada vez mais ele se constrói e molda a sociedade a partir da lógica de "o vencedor leva tudo". Portanto, é inevitável que a competitividade predisponha ao fracasso um número cada vez maior de pessoas educadas. O que é grave nisto é que inevitavelmente, com o tempo, levará cada vez mais as pessoas a se perguntarem: Escola para que? (Caruso, 2010).

Quanto à divulgação científica propriamente dita, precisamos inovar e ousar mais nas atividades propostas (Caruso, 2020). Ao planejá-las, não devemos nos preocupar tanto com o que gostaríamos de falar ou até mesmo de ouvir, se fôssemos nós o público-alvo a receber essa divulgação científica. Tampouco devemos pautar nosso planejamento no que entendemos ser importante para a formação de um jovem em uma particular área do conhecimento. Deveríamos, ao contrário, nos voltar mais para aquelas questões para as quais a ciência ainda não tem respostas, ou está em vias de obtê-las. Digo isso me lembrando das palavras do prêmio Nobel de Medicina, nascido em Petrópolis, Rio de Janeiro, Peter Brian Medawar, quando ele diz que são as crianças que fazem as perguntas mais difíceis para a ciência (Medawar, 1984).

É preciso também compartilhar com os jovens hoje em dia que a Ciência não lida com opiniões nem com verdades absolutas. A beleza desse fato só pode ser compreendida com a história da Ciência, por meio de exemplos que se relacionem com o questionamento do aluno.

Por fim, mas não menos importante, a história dos fracassos deve ter seu espaço também na divulgação científica. É com o erro que se aprende. Também é importante discutirmos com os jovens as questões para as quais ele tem uma curiosidade natural: - Quem teria sido o pai do primeiro homem? - Teria Adão tido umbigo? - O que veio primeira, o ovo ou a galinha? Por que um filho pode se parecer fisicamente com o pai se é a mãe que o leva na barriga? Não podemos absolutamente matar

\footnotetext{
${ }^{9}$ Frase pronunciada em sua palestra intitulada "Sobre o óbvio", ministrada no Congresso Anual da SBPF, em 1977.
} 
essa curiosidade ingênua das crianças e dos adolescentes. Lembrem-se do fato histórico que Einstein começou a pensar em problemas envolvendo a propagação da luz depois de ler, por volta dos seus quinze anos, um livro de divulgação científica, considerado um "livro menor". Mas, como disse Umberto Eco, não existem livros ruins. A qualidade está nos olhos do leitor. O que é relevante nesse exemplo para o tema que estamos tratando é que o contato daquele jovem com esse material de divulgação foi o ponto de partida para o desenvolvimento de seu pensamento que desembocou na Teoria da Relatividade Especial de 1905.

Nesse sentido, as escolas fariam um grande favor à ciência se ensinassem aos alunos incentivando-os sempre a fazerem perguntas, a questionar, a duvidar e não apenas a darem respostas a questões previamente formuladas. $\mathrm{O}$ primeiro desafio de qualquer cientista, invariavelmente, é encontrar um problema em aberto e formulá-lo corretamente. Propor um problema, muitas vezes, é mais complicado do que resolvê-lo. Essa essência do método científico, lamentavelmente, não faz parte da didática do ensino de Ciências. É urgente resgatá-la (Caruso, 2020).

Os processos políticos buscam muitas vezes criar e estimular uma "nova visão de mundo", sempre muito particular, que justifique o abandono de uma ou outra disciplina. Criam sistemas particulares de ensino que procuram tornar orgânica a transmissão de suas ideias centralizadoras, e, para isso, não é difícil encontrar a mistura "ideal" entre religião e ensino, facilitando a crença em substituição ao conhecimento, a doxa no lugar da episteme, além do surgimento de personagens "míticos". A Filosofia, por exemplo, é "vítima" recorrente desse processo. A linguagem de fé, dessa forma, ganha condições de se equiparar nos debates à linguagem da ciência, retroalimentando o fanatismo, como também nos diz Klemperer (2009) ao tratar da linguagem do III Reich.

\section{Considerações Finais}

Acreditamos na existência de um Zeitgeist e em seu impacto determinante em certo período histórico. Segundo Hobsbawn (2003), o surgimento de um capitalismo selvagem entre 1970 e 1990 dá origem a um futuro incerto num século que ele considera curto, a partir da deterioração de sistemas institucionais, que abre as portas para uma espécie de ditadura irresponsável da Economia, em especial de algumas correntes ortodoxas. A partir daí, começa a se difundir a ideia de que passado e futuro parecem dissociados do presente. O sujeito, imerso nesse novo mundo de mudanças cada vez mais rápidas, tem que se adaptar a novas realidades de trabalho e às redes sociais, pagando um alto preço com relação a seu caráter (como apontou Richard Sennett) e com relação à sua própria individualidade e personalidade (segundo Bauman), como discutindo anteriormente.

O Zeitgeist assim formado privilegia a mentira, a não preservação da memória (individual e coletiva) como parte de uma estratégia de reinventar continua e alucinadamente esse sujeito-consumidor. Sem a História é mais fácil manipular as pessoas, principalmente quando elas caem na armadilha do individualismo. $\mathrm{O}$ ataque sistemático à razão e à verdade são adotados como parte dessa estratégia maior de confundir e manipular a sociedade pós-contemporânea. Assinala-se, assim, o início do declínio da importância do discurso racional e do papel do bom senso, culminando com o malfadado conceito de "fatos alternativos", abordado com propriedade pela crítica literária norte-americana Michiko Kakutani (1955), em seu livro A morte da verdade, publicado em 2018.

É nesse pano de fundo que, hoje talvez verifiquemos aquilo que Carl Sagan (1934-1996) escreveu em 1995 na sua obra "O mundo assombrado por demônios", e que talvez esteja se concretizando. A sociedade mais adiantada tecnologicamente em nosso planeta, os EUA, convive com alta tecnologia, "abduções alienígenas" e terraplanismo, ajudando a disseminar no mundo ainda mais paranoias como o movimento denominado "QAnon". Algo medieval que ainda hoje não deixou de existir, fora do método científico, e que criou um ambiente propício para disseminar fake news e negacionismo científico, pois sempre é mais fácil acreditarmos naquilo que não se vê, no fruto direto da fé, qualquer que seja. 
Cabe notar que o esforço norte-americano para desenvolver a bomba atômica e vencer a II Guerra Mundial, representado pelo sucesso do Projeto Manhattan, inaugurou uma nova relação entre ciência básica e aplicada, entre laboratórios de pesquisa e indústria. Tal modelo serviu e ainda serve de paradigma para tais relações em várias partes do mundo. Um exemplo típico de sucesso é o CERN (Organização Europeia para Pesquisa Nuclear), localizado em Genebra, onde ciência básica e tecnologia de ponta são compartilhadas pelos países membros da Organização.

Criamos uma sociedade distópica, relativizada, na qual objetos inanimados e fama fugaz nas redes sociais ganham cada vez mais espaço e relevância, enquanto informações científicas não são vendáveis e sempre passíveis de serem rebatidas pela doxa (opinião). Isso mostra certa relação com o romance “1984” de George Orwell, (2009), que traça uma antevisão futurista do Big Brother que a tudo controlaria. A divulgação e o entendimento do que é ciência torna-se cada vez mais distante de ser objeto de atenção, e o desinteresse dos jovens pelo conhecimento desaparece aos poucos. Aquilo que vende e gera lucros justificaria a centralização do eu em nossa época, cada vez mais paranoica e doentia, com indivíduos que buscam encontrar em toda forma de violência maneiras de ganhar espaço.

O fato de termos de construir uma "nova modernidade", superando a liquidez de Bauman, não passará pela certeza de que as conquistas da ciência são dispensáveis, nem pelo tampouco pelo prevalecimento do senso comum opinativo deva ter a mesma prevalência em nosso habitat social. O novo "normal", sobre o qual falamos ao longo deste texto, já evidencia que ainda há muito a ser conquistado, e a necessidade de uma formação mais próxima da ciência para os mais jovens ainda que não seja garantia de um futuro melhor.

Assim como a democracia é imperfeita, mas ainda assim a melhor das opções políticas, o mesmo ocorre entre a episteme e a doxa. Teremos que superar os desafios dados pelos novos tempos, quando as técnicas organizacionais nascidas da fábrica da sociedade industrial revelam cada vez mais seus limites. O sujeito pós-moderno precisa se reinventar, sob pena de viver em uma sociedade egoísta e totalitária. Aqui é difícil não lembrar a posição otimista com que Sennett conclui seu livro sobre a corrosão do caráter, dando-nos esperança: "Mas sei que um regime que não oferece aos seres humanos motivos para ligarem uns para os outros não pode preservar sua legitimidade por muito tempo" (Sennett, 2003, p. 176).

É cada vez mais evidente que sem o domínio da ciência básica não há desenvolvimento tecnológico autônomo e sustentável. Haverá sempre uma dependência crescente dos países subdesenvolvidos em relação aos países que dominam a vanguarda de C\&T, caso não haja uma decisão firme de investir fortemente em Educação e em Ciência Básica, como tem feito, por exemplo, a Coreia do Sul, nos últimos 40 anos. Resta-nos aguardar que o Brasil realmente decida entrar para o seleto clube dos países desenvolvidos, que são os que mais investem nessas duas áreas estratégicas.

Deixamos aqui, então, um desafio final ainda a ser respondido, aos colegas interessados em divulgação científica, sob a forma de uma pergunta: o que cada um de nós pode fazer para fomentar a curiosidade tão indispensável à Ciência e, assim, combater a onda negacionista?

Enquanto isso, só nos resta esperar que se restaure a credibilidade na Ciência e na Razão, indispensáveis para um possível novo tipo de Iluminismo aberto ao diálogo com as Artes, que mais cedo ou mais tarde virá, trazendo com si um sujeito melhor, mais empático e preocupado com o bem coletivo e a continuidade da História, em uma continuidade libertária que se oriente pelos Direitos Humanos.

Concluindo, o assunto aqui abordado está longe de ser compreendido em todas as suas dimensões. Os autores têm interesse em continuar se dedicando a refletir sobre o tema. Em particular, gostariam de se dedicar aos efeitos da corrosão do caráter e outros problemas sociais apontados no presente ensaio sobre a instituição Escola. Outro aspecto não tratado aqui, que merece uma reflexão aprofundada, é a influência familiar na formação desse possível negacionismo prematuro. Estaria ele, por exemplo, ligado à perda do hábito de se lerem os clássicos infanto-juvenis para as crianças no ambiente familiar, deixando assim de lhes apresentar toda um embasamento moral e ético envolvido nas fábulas? Esse é só mais um exemplo que evidencia 
o quanto é amplo o espectro de temas que podem influenciar o negacionismo. Se nosso ensaio despertar o interesse de novas pessoas para a relevância de compreender e se opor ao negacionismo científico e ao negacionismo em geral terá cumprido seu papel.

\section{Referências}

Ascott, R. (1995). The architecture of cyberspace. Architectural design. Architects in cyberspace, Academy Editions, 11/12 (65), 38-41.

AVAAZ. Brasil está sofrendo uma infodemia de Covid-19. (2020). https://secure.avaaz.org/campaign/po/brasil_infodemia_coronavirus/.

Bacon, F. (2002). A sabedoria dos antigos. UNESP.

Bauman, Z. (1989). Modernidade e holocausto. Zahar.

Bauman, Z. (2000). Modernidade líquida. Zahar.

BBC News Brasil. (2020). Fuga de cérebros: os doutores que preferiram deixar o Brasil para continuar pesquisas em outro país. https://www.bbc.com/portuguese/brasil-51110626.

Bradbury, R. (2020). Fahrenheit 451. Editora Globo.

Caruso, F. (2010). A Corrosão do caráter... e da escola. Ciência e Sociedade, CS-001(010).

Caruso, F. (2013). Ciência Básica ou Aplicada? Faz sentido essa pergunta? Revista Eletrônica do Vestibular, 6(14), 1-2.

Caruso, F. (2020). Divulgação científica: antigos e novos desafios. Ciência e Sociedade, CBPF, 1 (7), 3-8.

Caruso, F., Marques, A.J \& Oguri, V. (2013). Galileu na sala de aula. Livraria da Física.

Caruso, F. \& Moreira, R. (2020). O livro, o espaço e a natureza: Ensaio sobre a leitura do mundo, as mutações da cultura e do sujeito. Livraria da Física.

Cioran, E. (2012). Nos cumes do desespero. Hedra.

De Masi, D. (1999). A Emoção e a Regra: os grupos criativos na Europa de 1850 a 1950. José Olympio.

De Masi, D. (2003). O futuro do trabalho. José Olympio.

De Masi, D. (2020). Entrevista dada à última edição do IT ForOn Series, série de conversas produzidas pelo Grupo IT Mídia e mediadas pelo jornalista Vitor Cavalcanti. https://cio.com.br/noticias/para-domenico-de-masi-o-lider-pos-pandemia-devera-pensar-em-sociedade/.

Descartes, R. (2006). Discurso do Método. L\&PM.

Eliade, M. (2013). O Sagrado e o Profano: A Essência das Religiões. Martins Fontes.

Estrela, C. (2018). Metodologia Científica: Ciência, Ensino, Pesquisa. Editora Artes Médicas.

Ferreira, M. L. \& Marques, A.J. (2019). A importância do incentivo à pesquisa para o ensino de química. Revista Educação Pública, 7(19), 1-6.

Geymonat, L. (1997). Galileu Galilei. Nova Fronteira.

Hobsbawn, E. J. (2003). Era dos Extremos: O Breve Século XX, 1914-1991. Companhia das Letras.

Kakutani, M. (2018). A Morte da Verdade. Intrínseca.

Klemperer, V. (2009). LTI, a linguagem do Terceiro Reich. Contraponto.

Marques, A. J. (2017). Diálogo entre as duas culturas. Gnarus Revista de História, 8(VIII), 179-184.

Marx, K. (2004) Manuscritos econômico-filosóficos. Editora Boitempo.

Medawar, P. (1984). The Limits of Science. Harper \& Row.

Krasnoff, R., Foster, G. \& Duval, C. (Produtores), Mick Jackson (Diretor). (2016). Negação (Denial) [filme]. USA: Sony Pictures, (109 min).

Nemer, D. (2021). David Nemer. https://www.dnemer.com/.

Orwell, G. (2009). 1984. Companhia das Letras.

Oz, A. (2016). Como curar um fanático. Companhia das Letras.

Peterson, J.B. (1999). Maps of Meaning: The Architecture of Belief. Routledge.

Rothman, T. (2005). Tudo é relativo. Difel. 
Research, Society and Development, v. 10, n. 11, e82101119538, 2021

(CC BY 4.0) | ISSN 2525-3409 | DOI: http://dx.doi.org/10.33448/rsd-v10i11.19538

Santoro, F. (2007). Arqueologia dos Prazeres. Objetiva.

Santaella, L. (2016). Temas e dilemas do pós-digital: a voz da política. Paulus.

Sennett, R. (2003). A corrosão do caráter, consequências pessoais do trabalho no novo capitalismo. Record. Thomas, J. R., Nelson, J. K. \& Silverman, S. J. (2007). Métodos de pesquisa. Artmed.

Vasconcelos, E. M. (2010). A associação entre vida religiosa e saúde: uma breve revisão de estudos quantitativos. RECIIS - R. Eletr. de Com. Inf. Inov. Saúde. $3(4), 12-18$. 